Article

\title{
Temporal and Spatial Variations in the Leaf Area Index and Its Response to Topography in the Three-River Source Region, China from 2000 to 2017
}

\author{
Wenqi Zhang ${ }^{1,2}$, Huaan Jin ${ }^{2, *}$, Huaiyong Shao ${ }^{1}$, Ainong Li ${ }^{2}$, Shangzhi Li ${ }^{3,4}$ and Wenjie Fan ${ }^{1}$ \\ 1 College of Earth Science, Chengdu University of Technology, Chengdu 610059, China; \\ wenqizhang@stu.cdut.edu.cn (W.Z.); shaohuaiyong@cdut.cn (H.S.); 2019020025@stu.cdut.edu.cn (W.F.) \\ 2 Research Center for Digital Mountain and Remote Sensing Application, Institute of Mountain Hazards and \\ Environment, CAS, Chengdu 610041, China; ainongli@imde.ac.cn \\ 3 School of Surveying and Land Information Engineering, Henan Polytechnic University, \\ Jiaozuo 454000, China; 211804010004@home.hpu.edu.cn \\ 4 Key Laboratory of Geospatial Technology for the Middle and Lower Yellow River Regions (Henan \\ University), Ministry of Education, Kaifeng 475004, China \\ * Correspondence: jinhuaan@imde.ac.cn
}

check for

updates

Citation: Zhang, W.; Jin, H.; Shao, H.; Li, A.; Li, S.; Fan, W. Temporal and Spatial Variations in the Leaf Area Index and Its Response to Topography in the Three-River Source Region, China from 2000 to 2017. ISPRS Int. J. Geo-Inf. 2021, 10, 33. https://doi.org/10.3390/ijgi10010033

Received: 26 October 2020 Accepted: 11 January 2021 Published: 13 January 2021

Publisher's Note: MDPI stays neutral with regard to jurisdictional clai$\mathrm{ms}$ in published maps and institutional affiliations.

Copyright: () 2021 by the authors. Licensee MDPI, Basel, Switzerland. This article is an open access article distributed under the terms and conditions of the Creative Commons Attribution (CC BY) license (https:// creativecommons.org/licenses/by/ $4.0 /)$.

\begin{abstract}
The Three-River Source Region (TRSR) is an important area for the ecological security of China. Vegetation growth has been affected by the climate change, topography, and human activities in this area. However, few studies have focused on analyzing time series tendencies of vegetation change in various terrain conditions. To address this issue in the TRSR, this study explored vegetation stability, tendency, and sustainability with multiple methods (e.g., coefficient of variation, Theil-Sen median trend analysis, Mann-Kendall test, and Hurst index) based on the 2000-2017 Global LAnd Surface Satellite Leaf Area Index (GLASS LAI) product. The differentiation patterns of LAI variations and multiyear mean LAI value under different topographic factors were also investigated in combination with digital elevation model (DEM). The results showed that (1) the mean LAI value in the study area increased, with a linear tendency of $0.013 \cdot 10 \mathrm{a}^{-1}$; (2) LAI values decreased from southeast to northwest in terms of spatial distribution and the CV indicated LAI variations were relatively stable; (3) the trend analysis revealed that the improved area of LAI accounted for $62.72 \%$ which was larger than the degraded area (37.28\%), and hurst index revealed a weak anti-sustaining effect of the current tendencies; and (4) the increasing trend was found in multiyear mean LAI value as relief amplitude and slope increased, while LAI stability improved with increasing slope. They exhibited a clear regular pattern. Moreover, significant improvement in LAI generally occurred in low-altitude and flat areas. Finally, the overall improvement and sustainability of LAI improved when moving from sunny aspects to shady aspects, but the LAI stability decreased. Note that vegetation degradation was observed in some high slope areas and was further aggravated. This study is beneficial for revealing the spatial and temporal changes of LAI and their changing rules as a function of different topographic factors in the TRSR. Meanwhile, the results of this study provide theoretical support for sustainable development of this area.
\end{abstract}

Keywords: Three-River Source Region; leaf area index; vegetation changes; topographic effect

\section{Introduction}

As an important part of terrestrial ecosystems, vegetation is the main component of land cover, is a key factor when considering the process of land-use changes and plays an essential role in interactions between the biosphere and atmosphere [1]. Located in the hinterland of the Tibetan Plateau, the Three-River Source Region (TRSR) is a typical alpine vegetation area. Under the various influences of human activity and natural factors, vegetation in some areas of the TRSR has been significantly degraded. Due to its ecological 
sensitivity and the importance of its geographical location, the region has attracted many scholars' attractions.

In the past few decades, the TRSR has experienced major climatic changes, such as significant increases in temperature [2-6], rainfall [7], solar radiation [8]. The coupling of these factors has greatly influenced the vegetation growth [9-13], which is constrained by different climatic factors in different regions [14]. Some studies have also shown that in some parts of the TRSR, grasslands are fragmented, and swamps have dried out $[15,16]$. Vegetation growth is a dynamic process that involves constant adaptation to the coupled interactions of ecosystem components [9]. The high heterogeneity and resulting ecosystem complexity of mountain environments have been shown to be important factors that influence vegetation growth [17-19] and have consequently lead to profound impacts on global climate [20,21], biodiversity [22,23], and terrestrial ecosystem productivity [24,25]. The topography of the TRSR is complex, with obvious vertical zonality and significant differences in human activities in the east-west direction, and there is high differentiation in the distribution patterns of vegetation changes in different terrains. Nevertheless, previous research has lacked systematic and comprehensive analyses of the relationships among vegetation change and topographic factors in both the temporal and spatial dimension. An in-depth understanding of vegetation changes in time series under different topographies is beneficial for implementing ecological construction projects such as natural grassland protection and soil erosion control in the TRSR.

Previous studies have used the normalization difference vegetation index (NDVI) to analyze temporal and spatial variations in vegetation cover; however, the NDVI tends to saturate during the vegetation growth period and is influenced by background soil disturbances [26]. Compared with the NDVI, the leaf area index (LAI) is more closely related to photosynthesis and vegetation transpiration and is an important factor when depicting energy exchange and material cycling between the Earth and the atmosphere. As one of the essential climate variables (ECVs) designated by the Global Climate Observing System (GCOS), the LAI is defined as one half of the sum of the total leaf area per unit of ground surface [27]. Currently, there are several datasets of satellite LAI products with global coverage and long time series [28], such as CYCLOPES (Carbon Cycle and Change in Land Observational Products from an Ensemble of Satellites) LAI [29], MODIS (Moderate Resolution Imaging Spectroradiometer) LAI [30], and GLASS (Global LAnd Surface Satellite) LAI [31,32]. Jin et al. [33] pointed out that the GLASS LAI dataset has higher data quality and smoother temporal profiles than the MODIS LAI dataset in Southwest China, making the GLASS LAI product more preferable for characterizing the temporal and spatial changes of vegetation cover.

In this context, this study uses the 2000-2017 GLASS LAI and digital elevation model (DEM) to quantitatively analyze spatial and temporal distributions, stability, trend, and sustainability of time series vegetation variations across different terrain conditions in the TRSR. The organization of this study is as follows. Section 2 presents the GLASS LAI product and DEM used in this paper and the processing strategy for these products. The method used to evaluate time series vegetation variations in the TRSR is also introduced in this section. Spatiotemporal analysis of vegetation changes and an overlay analysis between these LAI products and the DEM are described in Section 3. An interpretation of the results and an exploration of the cause of this phenomenon are discussed in Section 4 . Conclusions are presented in Section 5.

\section{Materials and Methods}

Annual mean LAI values were obtained from the 2000-2017 GLASS LAI data at $1 \mathrm{~km}$ pixel levels during the vegetation growing season, and DOY 129-289 data were selected as annual growing season data according to the literature [9]. Furthermore, the corresponding topographic factors were extracted from a $30 \mathrm{~m}$ DEM by aggregating to $1 \mathrm{~km}$ using a grid. Based on the annual growing season LAI, the overall spatial and temporal distributions of LAI characteristics were analyzed by using mathematical methods and GIS spatial analysis 
to identify the differences in LAI spatial distributions over 18 years. Furthermore, the stability of LAI changes was evaluated by using the CV method, and the LAI trends were also calculated using Theil-Sen median and Mann-Kendall tests. Hurst indices coupled with the Theil-Sen and Mann-Kendall test results were used to analyze LAI sustainability to clarify the spatial and temporal evolution of vegetation LAI values in the TRSR. Based on the practices mentioned above, a spatial overlay analysis was performed to obtain patterns of variations in vegetation trends and multiyear mean LAI values under different terrain conditions. The spatiotemporal characteristics of LAI and their response to rugged surfaces were further investigated in the TRSR (Figure 1).

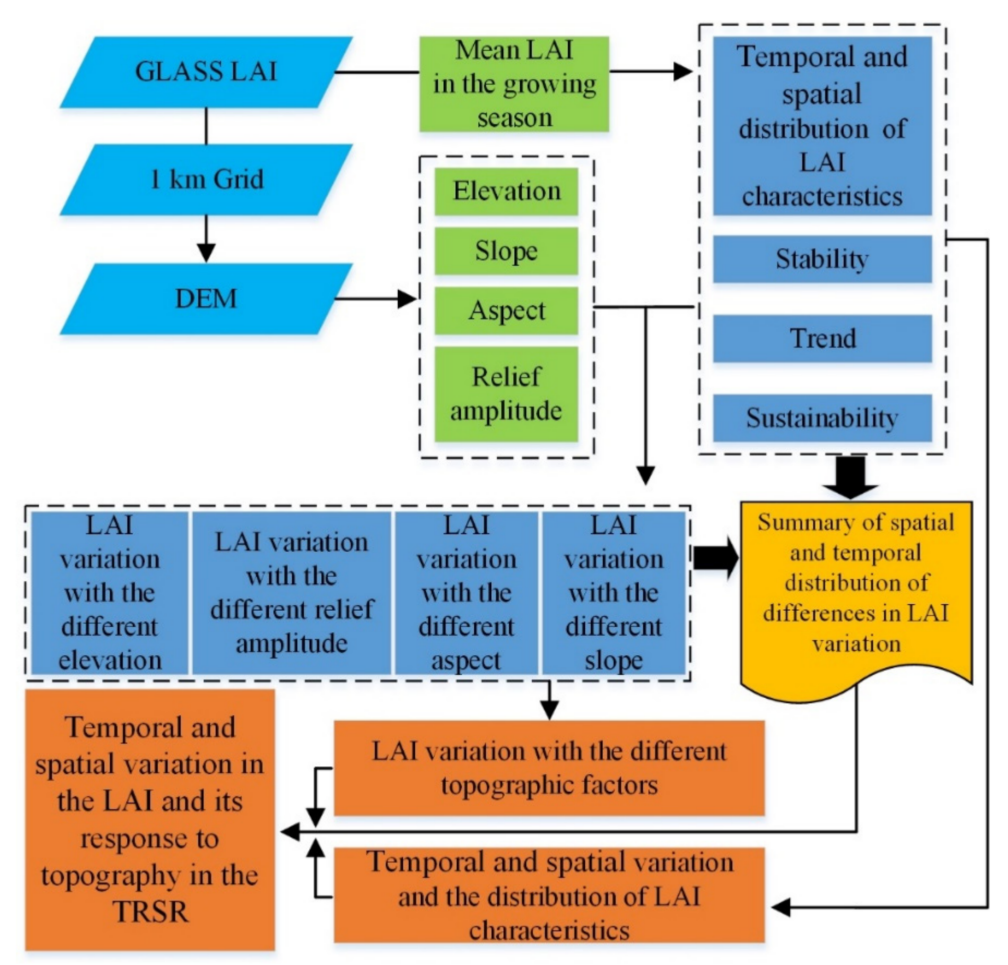

Figure 1. Flowchart of the study design.

\subsection{Study Area}

The TRSR is located in the hinterland of the Qinghai-Tibet Plateau in China (Figure 2) and contains the headwaters of the Yangtze, Yellow, and Lancang Rivers [9]. With its vast expanse and complex terrain, the TRSR is currently the largest and highest-elevation nature reserve in China. The average elevation is greater than $4000 \mathrm{~m}$. The study area for this research is located between $\mathrm{N} 31^{\circ} 39^{\prime}-36^{\circ} 16^{\prime}$ and $\mathrm{E} 89^{\circ} 24^{\prime}-102^{\circ} 23^{\prime}$, and the administrative cell includes 22 counties, such as Zhiduo and Qumalai, with a total area of approximately $369,000 \mathrm{~km}^{2}$. Alpine meadow (58.03\%) and alpine steppe $(24.48 \%)$ are the main vegetation types in the TRSR and cover the vast majority of the study area, which are followed by alpine vegetation $(9.58 \%)$, shrub $(6.35 \%)$, needleleaf forest $(1.25 \%)$, cultivated vegetation $(0.23 \%)$, and broadleaf forest $(0.06 \%)$. Among these vegetation types, alpine vegetation is mainly distributed in the northwestern part of the study area; shrubs are mainly distributed in the southern part of the study area, such as Banma, Jiuzhi, Gande, and Henan; and forests are mainly distributed in Yushu, Nangqian, Banma, Maqin, and Tongde [34-36]. As shown in Figure 3, the altitudes of the TRSR gradually decreases from northeast to southwest, with elevations of $4500-5000 \mathrm{~m}$ for $46 \%$ of the region and elevations less than $3500 \mathrm{~m}$ for only $7 \%$ of the region. Topographic relief is a macroscopic index that describes the topographic features of an area. It quantitatively describes the height differences or the heights of relief within a statistical cell [37], which decrease from northwest to southeast, with a relief amplitude of 100-200 m in most of the TRSR (32\%) and 1-100 m in the smallest percentage $(9 \%)$. The distribution of slope variations is broadly consistent 
with the variations in topographic relief. Slopes of $5-10^{\circ}$ are observed for the vast majority of the TRSR (36\%), and slopes of $0-5^{\circ}$ accounts for the smallest proportion (1\%). The vast majority of the TRSR is characterized by sunny slopes, with $57 \%$ south-facing slopes, $21 \%$ southeast-facing slopes, and 16\% southwest-facing slopes; the other slopes present are west-, northwest-, north-, and northeast-facing slopes, which account for a small portion of slopes with a relief range of $0-5^{\circ}$.

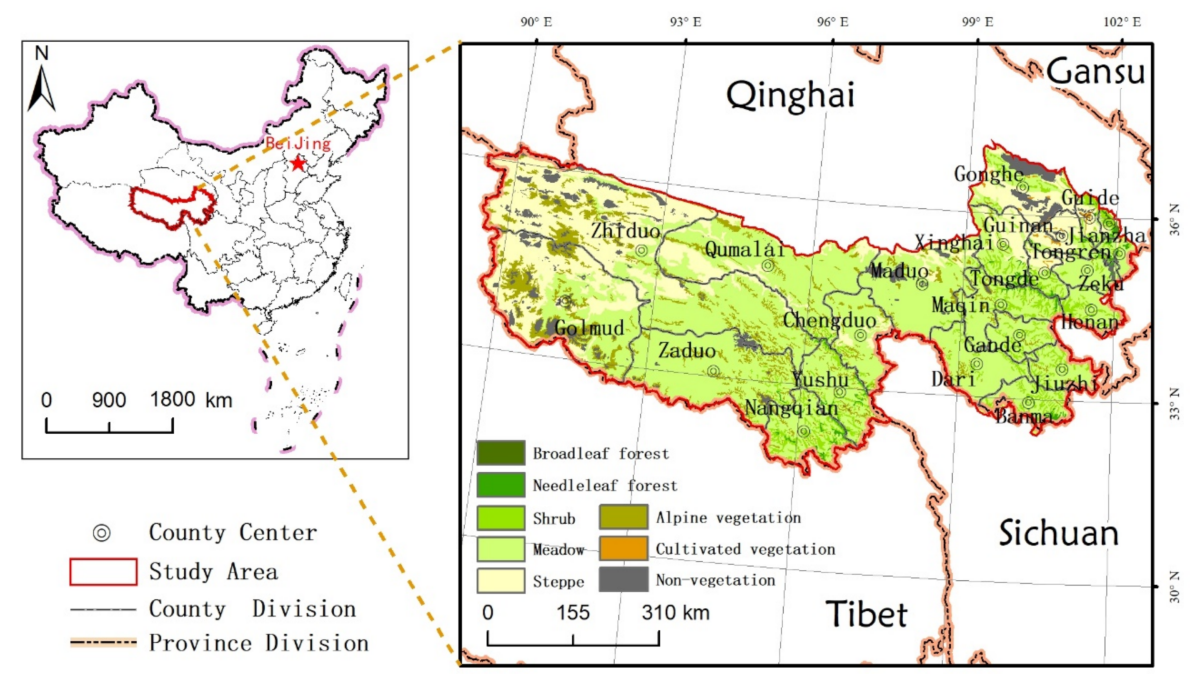

Figure 2. Study area. Vegetation types are extracted from the 1:1,000,000 vegetation map of the People's Republic of China [34].
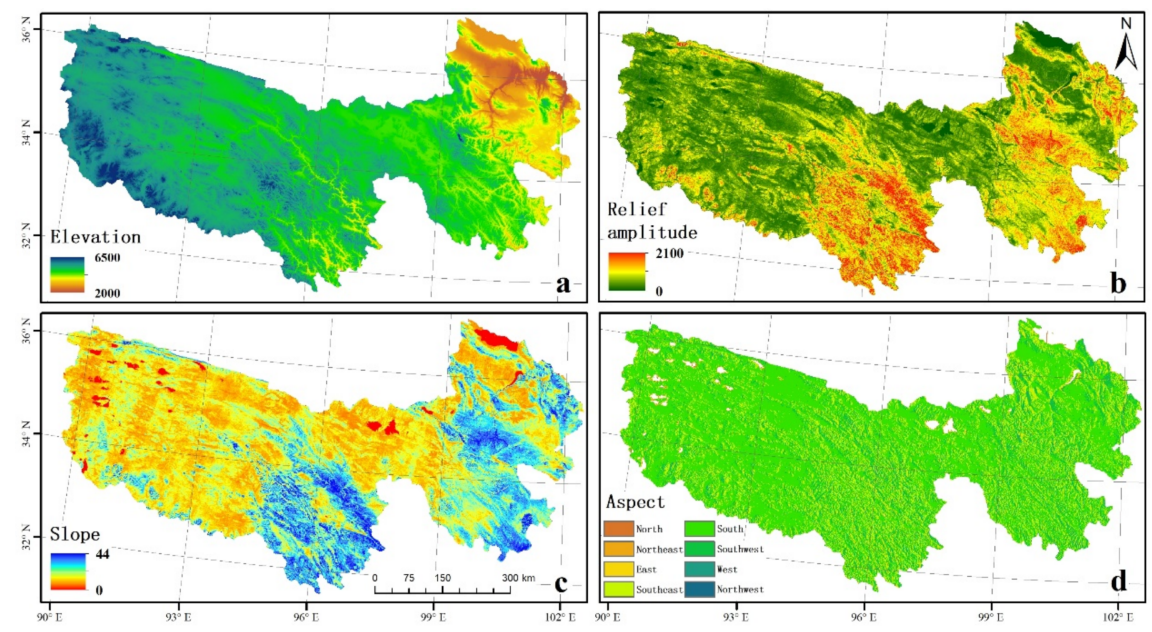

Figure 3. Various topographic factors in the TRSR: (a) elevation, (b) relief amplitude, (c) slope, and (d) aspect.

\subsection{Data and Preprocessing}

(1) The GLASS LAI product was obtained from the Nation Earth System Data Center, National Science \& Technology Infrastructure of China (http:/ / www.geodata.cn). It was provided in a sinusoidal projection with a spatial resolution of $1 \mathrm{~km}$ and temporal resolution of 8 days and covered the period from February 2000 to December 2017. The GLASS LAI algorithm is introduced briefly as follows: firstly, the effective CYCLOPES LAI is converted to the true LAI, and then combined with the MODIS LAI according to the individual uncertainties through comparison with the ground-measured true LAI datasets; subsequently, GRNNs are trained using the fused LAI and reprocessed MODIS reflectance for each biome type to estimated GLASS LAI profiles [31]. In this paper, MRT (MODIS Reprojection Tools) and ArcGIS 10.5 software were used for format conversion from HDF 
to GeoTiff and then reprojected to the Albers Equal Area World Geodetic System - 1984 Coordinate System (AEA_WGS_1984). After that, the mean composition was used to obtain the temporal LAI dataset for the 2000-2017 growing seasons in the study area.

(2) Topographic data used were obtained from the Advanced Spaceborne Thermal Emission and Reflection Radiometer Global Digital Elevation Model version 2 (ASTER GDEM v2) with a spatial resolution of $30 \mathrm{~m}$ (http:/ / www.gscloud.cn). ArcGIS 10.5 software was used to reproject, mosaic and clip the data; extract elevations, relief amplitudes, slopes and aspect information; and extract the corresponding regional terrain factors based on a 1 $\mathrm{km}$ grid, which was generated from the image using zonal statistics. By using literature conventions [38] and based on the current features of the study area, elevations were divided into five categories (e.g., $<3500 \mathrm{~m} ; 3500-4000 \mathrm{~m} ; 4000-4500 \mathrm{~m} ; 4500-5000 \mathrm{~m}$; and $>5000 \mathrm{~m}$ ); relief amplitudes were divided into five categories (e.g., 0-100 m, 100-200 m, 200-300 m, 300-400 m, and $>400 \mathrm{~m}$ ); slopes were divided into five categories (e.g., $0-5^{\circ}$, $5-10^{\circ}, 10-15^{\circ}, 15-20^{\circ}$, and $>20^{\circ}$ ); and aspects were divided into eight categories (e.g., north, northeast, east, southeast, south, southwest, west, and northwest).

\subsection{Research Methodology}

\subsubsection{Analysis of Spatial Variability}

The coefficient of variation (CV) indicates the degree of dispersion of the data, which reflects the interannual fluctuation characteristics of the LAI. It is calculated using the standard deviation of a series divided by the arithmetic mean. The equation is as follows:

$$
C V=\frac{\delta}{\bar{x}}
$$

where $\bar{x}$ denotes the mean value of the 2000-2017 LAI and $\delta$ denotes the standard deviation of the 2000-2017 LAI. Larger CV values indicate that vegetation activity has exhibited large fluctuations over the years, and smaller $C V$ values indicate that vegetation activity has been more stable. Note that to explore the statistical pattern between LAI stability and mean LAI value with topographic factors, we calculated the mean values and standard deviations of $C V$ and LAI in each terrain grading, and ordinary least squares regression was used to fit them.

\subsubsection{Theil-Sen Analysis and Mann-Kendall Test}

Theil-Sen analysis and the Mann-Kendall test have been increasingly applied to long time-series analyses of vegetation. The equation is as follows:

$$
\beta=\operatorname{Median}\left(\frac{X_{j}-X_{i}}{j-i}\right), 2000 \leq i<j \leq 2017
$$

where Median is a function, $X_{j}$ and $X_{i}$ are the LAI data, and $\beta$ indicates the trend in the LAI, where $\beta>0$ indicates that the LAI is trending up, and $\beta<0$ indicates that the LAI is trending down. The determination of the trend significance is supplemented by the Mann-Kendall test. This method was originally proposed by Mann [39] and is performed as follows.

$$
\begin{gathered}
Z_{S}=\left\{\begin{array}{l}
\frac{S-1}{\sqrt{\operatorname{var}(S)}}, S>0 \\
0, S=0 \\
\frac{S+1}{\sqrt{\operatorname{var}(S)}}, S<0
\end{array}\right. \\
S=\sum_{j=1}^{n-1} \sum_{i=j+1}^{n} \operatorname{sgn}\left(X_{j}-X_{i}\right) \\
\operatorname{sgn}\left(X_{j}-X_{i}\right)=\left\{\begin{array}{l}
1,\left(X_{j}-X_{i}\right)>0 \\
0,\left(X_{j}-X_{i}\right)=0 \\
-1,\left(X_{j}-X_{i}\right)<0
\end{array}\right.
\end{gathered}
$$




$$
\operatorname{var}(S)=\frac{n(n-1)(2 n+5)-\sum_{i=1}^{m} t_{i}\left(t_{i}-1\right)\left(2 t_{i}+5\right)}{18}
$$

where $X$ denotes the LAI time series data-set; $X_{j}$ and $X_{i}$ denote the LAI values of year $j$ and year $i$, respectively; $n$ denotes the length of the time series; sgn is the symbolic function; $m$ is the number of recurring data-sets in the series; and $t_{i}$ is the number of repeated data-sets in the group $i$. By referring to the literature [40] and the actual features of the study area, areas with $\beta>0$ were classified as improved areas, areas with $\beta<0$ were classified as degraded areas, and the test results were used to classify significant changes $\left(Z_{s}>1.96\right.$ or $\left.Z_{s}<-1.96\right)$ and nonsignificant changes $\left(-1.96 \leq Z_{s} \leq 1.96\right)$ at the 0.05 confidence level.

\subsubsection{Hurst Index}

The Hurst index, which is based on the $R / S$ analysis method, was proposed by the British hydrologist Hurst in 1965 [41]. The ratio of the range to the standard deviation $(R / S)$ is calculated, and the Hurst index is obtained using least-squares fitting, which is based on the following principles:

For the time series $\{L A I(t)\}, t=1,2 \ldots n$, define the mean series.

$$
\begin{gathered}
\overline{\operatorname{LAI}}_{(\lambda)}=\frac{1}{\lambda} \sum_{t=1}^{\lambda} \operatorname{LAI}(t) \lambda=1,2 \ldots n \\
X_{(t, \lambda)}=\sum_{t=1}^{\lambda}\left(L A I_{(t)}-\overline{L A I}_{(\lambda)}\right) 1 \leq t \leq \lambda \\
R_{(\lambda)}=\max _{1 \leq t \leq \lambda} X_{(t, \lambda)}-\min _{1 \leq t \leq \lambda} X_{(t, \lambda)} \lambda=1,2 \ldots n \\
S_{(\lambda)}=\left[\frac{1}{\lambda} \sum_{t=1}^{\lambda}\left(L A I_{(t)}-\overline{L A I}_{(\lambda)}\right)^{2}\right]^{\frac{1}{2}} \lambda=1,2 \ldots n
\end{gathered}
$$

where $H$ in the ratio $R_{(\lambda)} / S_{(\lambda)} \propto(\lambda)^{H}$ is the Hurst index of the data over the analyzed years, and it has a range of $(0,1)$. When $0<H<0.5$, the current trend is opposite to the past trend, and the closer $H$ is to 0 , the stronger the inverse sustainability. $H=0.5$ suggests an independent time series. When $0.5<H<1$, the current trend is consistent with the past trend, and the closer $H$ is to 1, the stronger the sustainability. According to the literature [42], the Hurst index classifies the entire area into four types: $(0,0.35)$ is defined as strongly anti-sustainable; $(0.35,0.50)$ as weakly anti-sustainable; $(0.50,0.65)$ as weakly sustainable; and $(0.65,1)$ as strongly sustainable.

\section{Results}

\subsection{Characteristics of the Overall LAI Distribution}

\subsubsection{Time-Varying Characteristics}

Growing season LAI values reflect vegetation changes in the TRSR. The mean value of the LAI in the growing season is approximately $0.72-0.80\left(\mathrm{~m}^{2} / \mathrm{m}^{2}\right)$, and the overall interannual variations show a slow growth rate of approximately $0.013 \cdot 10 \mathrm{a}^{-1}(p>0.05)$. The overall LAI values show an increasing trend in 2000-2005, and then decrease during 2005-2008. Subsequently, the values of LAI increase again in 2008-2010, and continue to fluctuate slightly after 2010 (Figure 4). 


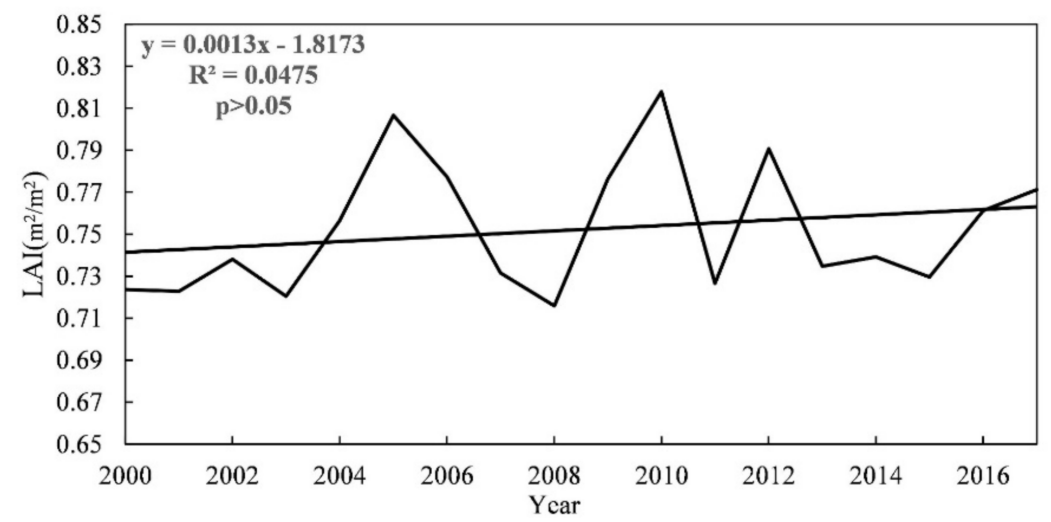

Figure 4. Line chart of mean leaf area index (LAI) during the vegetation growing season from 2000 to 2017 in the TRSR.

\subsubsection{Spatial Distribution Characteristics}

A mean LAI map for the growing seasons over 18 years was composited using the mean composition method to obtain the multiyear LAI spatial distribution, as shown in Figure $5 \mathrm{a}$, with an overall mean value of 0.78 . Note that unvegetated areas accounted for $7.8 \%$ of the total study area.
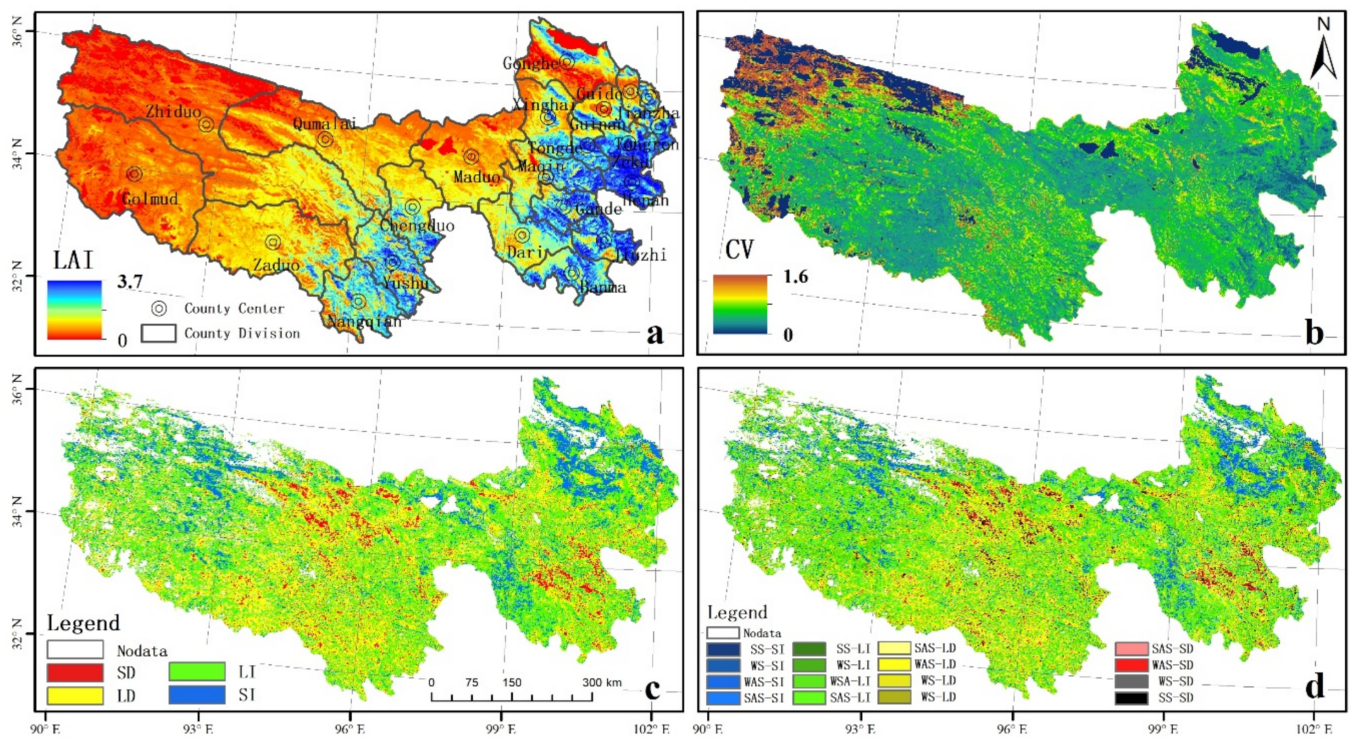

Figure 5. Spatial distributions and spatial variations in time series LAI changes for the growing seasons in the TRSR from 2000 to 2017: (a) multi-year average values, (b) stability, (c) trend, and (d) sustainability. SD represents significant degradation, LI represents lightly improvement, LD represents lightly degradation, SI represents significant improvement, SS represents strongly sustainable, WS represents weakly sustainable, SAS represents strongly anti-sustainable, and WAS represents weakly anti-sustainable.

The CV of the LAI ranges between 0 and 1.6 (Figure $5 b$ ), with a mean value of 0.18 . The whole region displays strong stability in LAI values, and the most obvious variations are mainly distributed in areas with low vegetation cover, such as Zhiduo, Golmud, northwestern Qumalai, Gonghe, Guinan, southeastern Zhiduo, and southwestern Nangqian.

Trend analysis reveals an overall increase in vegetation activity in the TRSR (Figure 5c), with $5.00 \%$ of the area being significantly degraded (SD), 32.28\% lightly degraded (LD), $50.09 \%$ lightly improved (LI), and $12.63 \%$ significantly improved (SI). Most of the areas with significant improvement or degradation are located in the following districts: (1) significant 
improvements in northeastern districts (e.g., Xinghai, Tongde, Zeku, Guinan, Gonghe, Guide, Tongren, and Jianzha); (2) significant improvements in the northwestern part of Zhiduo and Qumalai; (3) significant improvements in regions southwest of Dari and northwest of Maduo; (4) significant degradation in regions northeast of Dari and east of Maduo, Maqin, Gande, Jiuzhi, and Banma; and (5) significant degradation in regions southeast of Zhiduo, in regions southwest of Chengduo and Qumalai, and in Zaduo. In other areas, such as Golmud city, the distribution of significant changes in the LAI is scattered.

The Hurst index of the LAI displays a mean value of 0.47 , which suggests overall weak vegetation sustainability. In total, $10.91 \%$ of the study area is strongly anti-sustainable (SAS), and $54.86 \%$ is weakly anti-sustainable (WAS). Moreover, $30.78 \%$ is weakly-sustainable (WS), while $3.45 \%$ is strongly-sustainable (SS). The results of LAI trend analysis are combined with the Hurst index results to obtain the spatial distribution of variations in LAI characteristics in growing seasons in the TRSR (Figure 5d). Significant degradation will further aggravate in the northeast of Dari, several similar cases has found in eastern Maduo, Gande, Jiuzhi, and Banma etc.

\subsection{Variation Characteristics of LAI with Topographic Factors}

The results of multiyear mean LAI value and its change tendency across different elevations are shown in Figures 6-8: (1) the mean LAI value rises with increasing altitude where elevation is lower than $3500 \mathrm{~m}$, and decreases with increasing elevation when the altitude is greater than $3500 \mathrm{~m}$; (2) the LAI stability tends to increase first and then decrease with increasing elevation, with the lowest variations at the $3500-4000 \mathrm{~m}$ level being the most stable and the highest variations at the greater than $5000 \mathrm{~m}$ level being the least stable; (3) the proportion of significant LAI improvement decreases gradually with increased elevation, in which the proportion of significant degradation initially increases, and then decreases, with the largest inflection occurring at elevations of 3500-4500 m; and (4) all four sustainability ratios of significant LAI improvement decrease with increased elevation, and the proportions of the four sustainability types with significant degradation first increase and then decrease with increased elevation, with the largest proportions of strong sustainability and significant degradation occurring at 3500-4500 m. Moreover, the largest proportions of strong anti-sustainability and significant degradation occurs at $4000-4500 \mathrm{~m}$. In addition, the largest proportions of weak sustainability and weak anti-sustainability and significant degradation occurs at $3500-4000 \mathrm{~m}$.
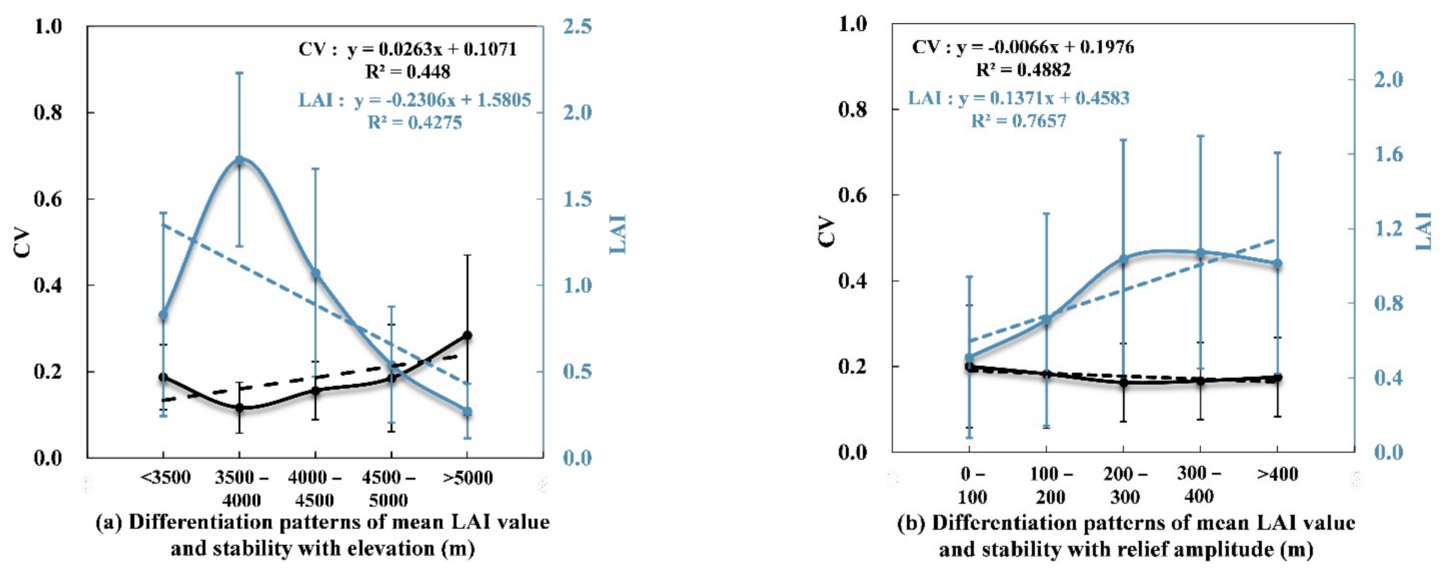

Figure 6. Cont. 


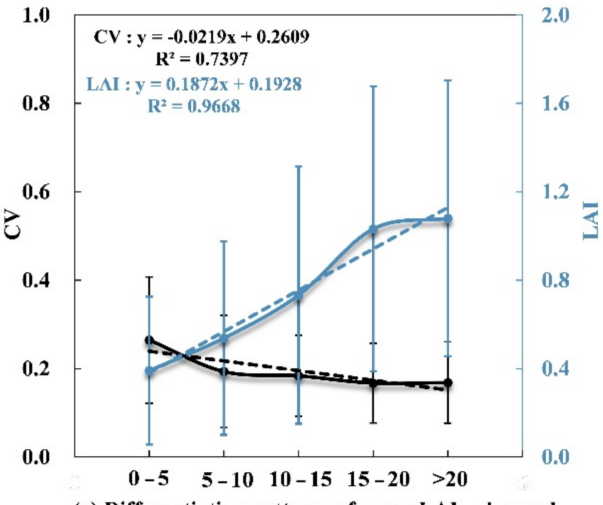

(c) Differentiation patterns of mean LAl value and stability with slope $\left(^{\circ}\right)$

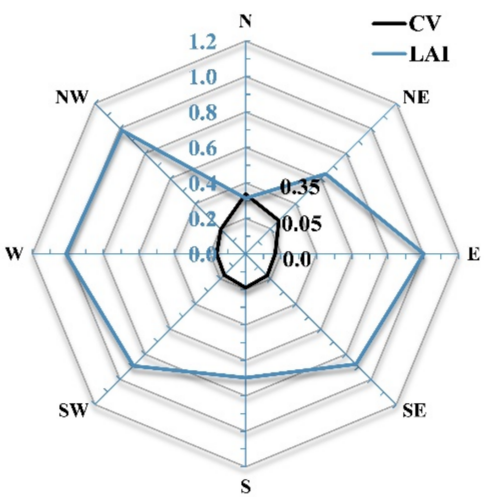

(d) Differentiation patterns of mean LAI value and stability with aspect

Figure 6. Differentiation patterns of mean LAI value and stability with (a) elevation, (b) relief amplitude, (c) slope, and (d) aspect. Vertical lines indicate the standard deviations of CV and mean LAI value in (a) elevation, (b) relief amplitude, and (c) slope. Moreover, the dotted line represents the results of ordinary least squares regression.

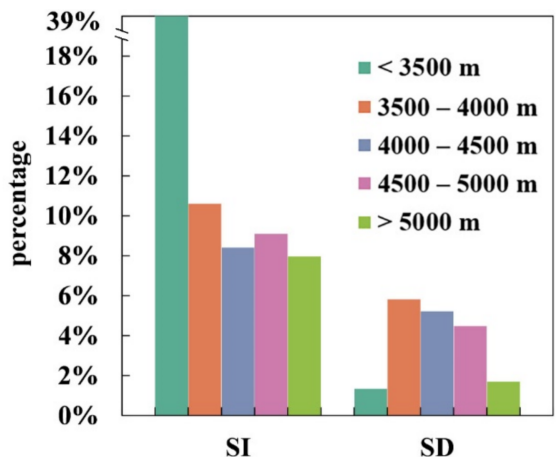

(a) Differentiation patterns of significant LAI trend with elevation

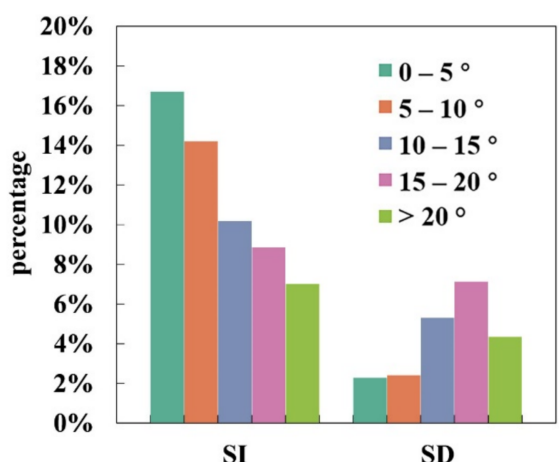

(c) Differentiation patterns of significant LAI trend with slope

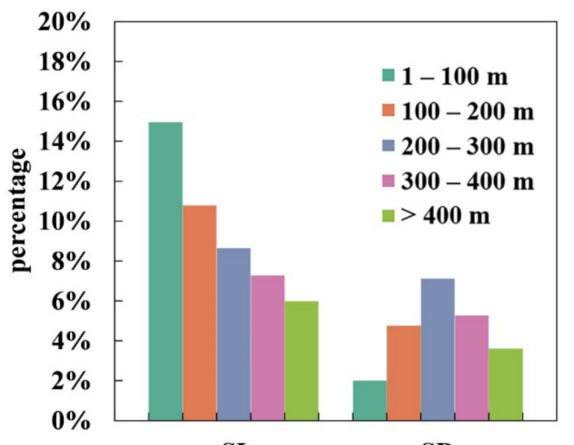

(b) Differentiation patterns of significant LAI trend with relief amplitude

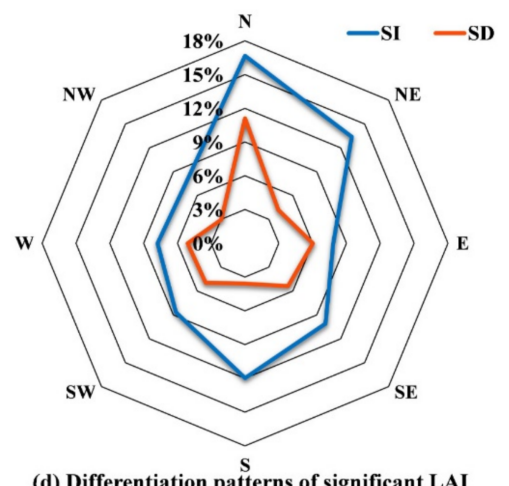

(d) Differentiation patterns of significant LAI trend with aspect

Figure 7. Differentiation patterns of significant LAI trends with (a) elevation, (b) relief amplitude, (c) slope, and (d) aspect. Meanings of the abbreviations are shown in Figure 5. 

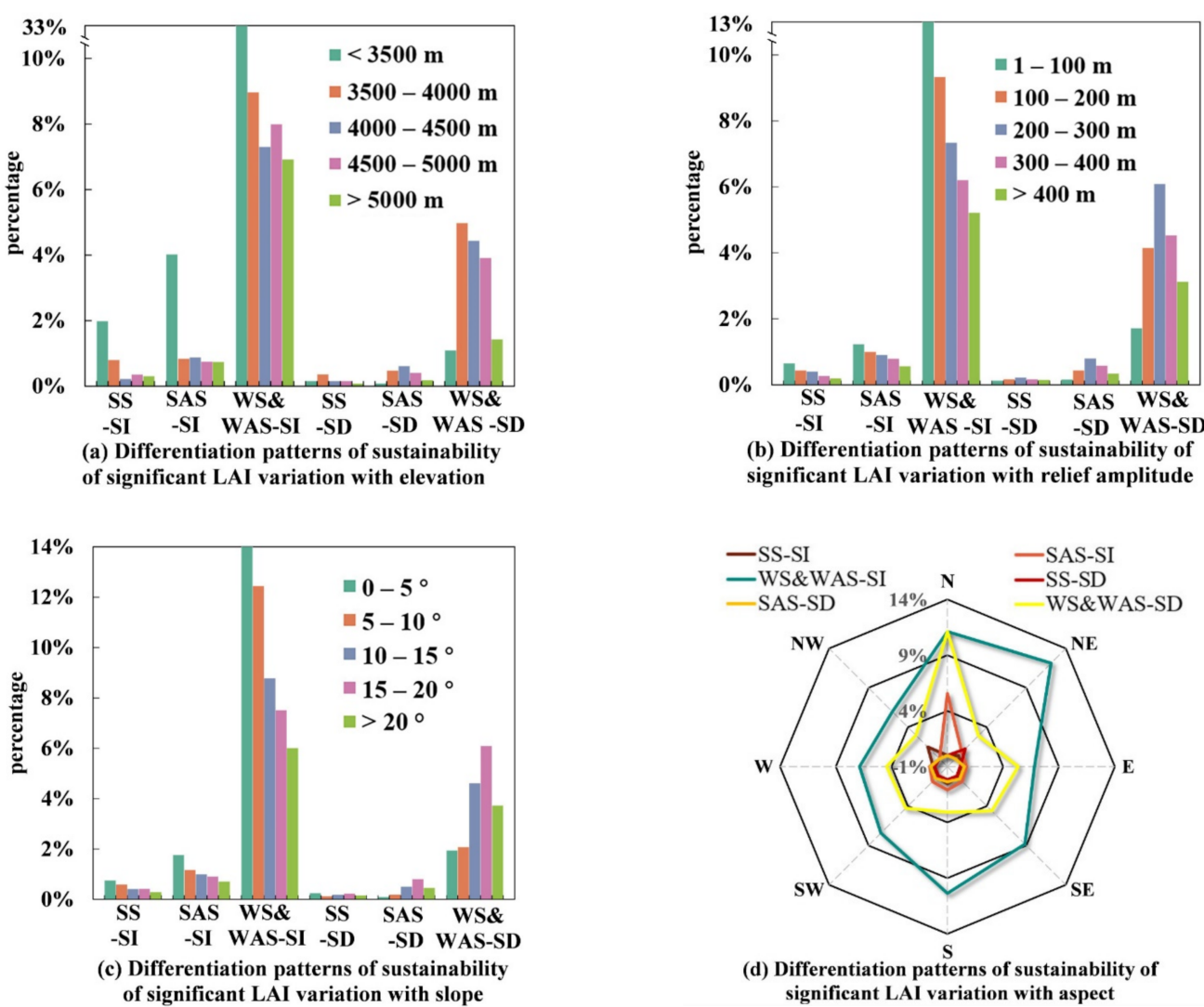

Figure 8. Differentiation patterns of sustainability of significant LAI variation with (a) elevation, (b) relief amplitude, (c) slope, and (d) aspect. Meanings of the abbreviations are shown in Figure 5.

The analysis of LAI variations with different relief amplitudes (Figures 6-8) shows as the following: (1) the mean LAI value becomes high as the relief amplitude increases and has a clear mathematical pattern $\left(\mathrm{R}^{2}=0.7657\right)$; $(2)$ the LAI stability tends to increase and then decrease as the degree of topographic relief increased, with the greatest stability in the 200-300 $\mathrm{m}$ range and the lowest stability in the lower than $100 \mathrm{~m}$ range; (3) the proportion of significant improvement in the LAI decreases as the degree of relief amplitude increases, and the proportion of significant degradation tends to increase first and then decrease, with the largest inflection occurring in the 200-300 m range; and (4) frequency of four sustainability with significant LAI improvements decreases as the degree of relief amplitude increases. The percentages of the four sustainability types with significant degradation tend to increase first and then decrease, with the largest percentages appearing in the 200-300 $\mathrm{m}$ range.

The analysis of LAI variations with different slopes (Figures 6-8) was revealed as the following: (1) the mean LAI value tends to improve as the degree of slope increases and has a clear mathematical pattern $\left(\mathrm{R}^{2}=0.9668\right)$; (2) the LAI stability increases with increasing slope and has a clear mathematical relationship $\left(\mathrm{R}^{2}=0.7397\right)$; (3) the proportions of significant improvements in LAI decrease gradually with increasing slope, and the proportions of significant degradation tend to increase at first and then decrease, with the largest inflection occurring in the $15-20^{\circ}$ level; and (4) the proportions of the four types of LAI sustainability with significant improvement decrease with increasing slope, and the proportions of the four sustainability types with significant degradation first increase and then decrease with increasing slope, with the largest proportion appearing in the $15-20^{\circ}$ range.

The analysis of LAI variations with different aspects (Figures 6-8) suggests the following: (1) there is no clear pattern between mean LAI value and aspects. Particularly, the largest mean LAI value is found in the west aspects, while the smallest exists in the north aspects; (2) LAI stability among aspects indicate that sunny aspects were overall 
more stable than shady aspects; (3) significant variation in the LAI account for the largest proportion of changes for the north aspect (with a significant improvement of $16.67 \%$ and significant degradation of $11.11 \%$ ) and the smallest for the northwest aspect (with a significant improvement of $7.46 \%$ and significant degradation of $2.99 \%$ ); and (4) the largest proportion of strongly sustainable significant improvement in the LAI is observed for northwest aspects $(1.49 \%)$, the largest proportion of strongly anti-sustainable significant improvement in the LAI is observed for north aspects (5.56\%), the largest proportion of strongly sustainable significant degeneration in the LAI is observed for northeast aspects $(1.26 \%)$, and the largest proportion of strongly anti-sustainable significant degradation in the LAI is observed for southeast aspects $(0.56 \%)$.

\section{Discussion}

The Tibetan Plateau, as the highest and largest natural geographical unit on Earth, and its hinterland, the TRSR, regulate climate change and water resources throughout Asia. Based on previous studies, this paper further discussed the spatiotemporal heterogeneity of vegetation changes in the TRSR over different terrains, which can provide references for vulnerability assessments of mountainous vegetation, regulation of water cycle processes and evaluations of ecological service functions. Table 1 shows in detail that the time series trends in LAI are consistent with those presented in the literature [3,9,10,43-45]. Compared with NDVI, the LAI has a clear ecological meaning and can more accurately characterize the spatial distributions and temporal variations in vegetation under complex topographic conditions.

Table 1. A Comparison between this study and previous studies.

\begin{tabular}{|c|c|c|c|c|}
\hline Reference & Indicator & Sensor & Time Span & Trend \\
\hline This study & GLASS LAI & AVHRR & $\begin{array}{c}\text { 2000-2017 } \\
\text { (growing season) }\end{array}$ & $\begin{array}{c}\text { The overall rate of increase is } \\
0.0013\left(\mathrm{~m}^{2} / \mathrm{m}^{2}\right) / \text { year }\end{array}$ \\
\hline $\begin{array}{l}\text { Liu et al. } \\
\text { (2014) [3] }\end{array}$ & SPOT-VGT & SPOT-VEGETATION & 1998-2012 & $\begin{array}{c}\text { The overall rate of increase is } \\
0.004 / \text { year }\end{array}$ \\
\hline $\begin{array}{l}\text { Du et al. } \\
\text { (2016) [9] }\end{array}$ & GIMMS NDVI3g & AVHRR & $\begin{array}{c}\text { 1982-2012 } \\
\text { (growing season) }\end{array}$ & $\begin{array}{l}\text { The overall rate of increase is } \\
0.0012 / \text { year }\end{array}$ \\
\hline $\begin{array}{l}\text { Liu et al. } \\
\text { (2013) [10] }\end{array}$ & MOD13Q1 & MODIS & 2000-2011 & $\begin{array}{c}\text { The overall rate of increase is } \\
0.12 / \text { year }\end{array}$ \\
\hline $\begin{array}{l}\text { Qian et al. } \\
\text { (2010) [43] }\end{array}$ & $\begin{array}{l}\text { NOAA/AVHRR } \\
\text { Pathfinder }\end{array}$ & AVHRR & 1982-2006 & $\begin{array}{c}\text { The overall rate of increase is } \\
0.0014 / \text { year }\end{array}$ \\
\hline $\begin{array}{l}\text { Xu et al. } \\
(2018)[44]\end{array}$ & MOD13Q1 & MODIS & $\begin{array}{c}\text { 2003-2014 } \\
\text { (growing season) }\end{array}$ & $\begin{array}{c}\text { The overall rate of increase is } \\
0.0029 / \text { year }\end{array}$ \\
\hline $\begin{array}{l}\text { Shen et al. } \\
\text { (2018) [45] }\end{array}$ & MODND1T & MODIS & 2000-2015 & $\begin{array}{c}\text { The overall rate of increase is } \\
0.02 / \text { year }\end{array}$ \\
\hline
\end{tabular}

\subsection{Analysis of LAI Variation with Topographic Factors in the TRSR}

The spatial distributions of LAI values decreased along a gradient from southeast to northwest throughout the TRSR, and the LAI values did not saturate in more than two-thirds of the regions. The reason is that the LAI values are mainly derived from the optical remote sensing signal, and many papers $[29,46]$ have shown that underestimation occurs when the LAI is greater than three or four due to the saturation of the optical reflectance. Fortunately, in this study, the LAI did not show the saturation phenomenon, which indicated that the use of LAI products was more conducive to the vegetation analysis of time series in the TRSR (Figure 5a). Further, high altitudes and low slopes and relief amplitudes with soil desertification areas (e.g., Zaduo, Golmud, Zhiduo, northern Chengduo, Qumalai, and Maduo) have low temperatures and monotypic vegetation communities, and the low sensitivity of leaves to changes in rainfall [6,47]. This environment has resulted in small-scale, mild, and continuous desertification of grasslands in this region. This, coupled with bare rocks, water bodies, and other unvegetated areas, has resulted in low LAI values in the northwest and north. Meanwhile, the grasslands are less degraded [48] in the eastern counties (e.g., the southern part of Chengduo, Yushu, Nangqian, 
central Chengduo, Zeku, and Tongde) with high slopes and relief amplitudes and low elevations (Figure 3), and human activities play a positive role in this region, hence the LAI values were high (Figures $5 \mathrm{a}$ and $6 \mathrm{a}-\mathrm{c}$ ). Additionally, the large east-west difference in LAI stability and overall weak variability in the TRSR can be attributed to the following: (1) the LAI has a large basic value, and the degree of interannual variation is mild. (2) The northwest is less stable due to the low LAI values and the small changes in vegetation that cause large fluctuations in CV values [49] (Figures 5b and 6).

The complex geometry of mountain surfaces and the random and disparate nature of their physical processes and ecological functions give rise to a high degree of spatial and temporal heterogeneity. Subsequently, materials (e.g., soil, mineral and water) migrate faster in the mountains under the influence of gravitational potential energy, which drastically changes the land surface shape in a short period of time and, at the same time, redistributes energy and nutrients, so the coupling of components is closer. On the other hand, the high concentration of environmental gradients in the mountains limits human to access, which affects the distribution and growth of vegetation [18]. As mentioned above, this study determined that the vegetation in the northwestern part of Zhiduo has undergone significant improvement (Figure 5c), which may be attributable to the improved vegetation growth at higher elevations due to reduced human activities and pollution. Nevertheless, this high-elevation area is extremely unfavorable for vegetation growth, and the rugged surface tends to hinder vegetation adaptability (Figure 3). More attention should be paid to these high-elevation and rugged areas in the future.

The central part of the TRSR (e.g., Zaduo, Qumalai, southwestern Chengduo, and southeastern Zhiduo) shows a trend of significant degradation, which will become more severe in the future (Figure $5 c, d$ ). This may be attributed to the high degree of the fragmentation of grasslands, the continuous degradation of grasslands [15], and irregular nutrients distribution in the soil. Moreover, the southern TRSR (e.g., northeastern Dari, eastern Maduo, Maqin, Gande, Jiuzhi, and Banma counties) has a high degree of vegetation degradation. This may be due to the steep slopes and complex relief amplitudes in the area around the interlocking distribution of canyons (Figure 3). Therefore, the soils are susceptible to erosion, and swamps dry out. Human activities has also negative impacts on the grassland in this region [15], and further results in a serious threat of vegetation growth (Figure 5d).

Vegetation in the northeastern and central parts of the TRSR has shown significant improvement (Figure 5c), which may be due to the lower elevations and flatter terrain (Figure 3). Furthermore, the implementation of ecological projects has significantly improved vegetation growth in Tongde, Zeku, Xinghai, and western Dari since 2000, with a large increase in LAI. However, the Gonghe Basin, which in the northeastern TRSR is the most serious land desertification areas with lowest LAI values, and interannual variations in rainfall hinders surface runoff; therefore, future growth of vegetation is not promising (Figure $5 \mathrm{~d}$ ).

LAI stability gradually improves with increasing slope (Figure $6 \mathrm{c}$ ), and the proportions of significant improvement decreases with increasing slopes and relief amplitudes (Figure 7b,c), probably because (1) vegetation on flat slopes and low relief amplitudes areas in the northwestern part of the study area is less disturbed by negative anthropogenic factors, especially for the $0-5^{\circ}$ range, which mostly presents a northern aspect and a near-water zone exhibiting low LAI values (Figure 6d), and (2) the flat slopes and low relief amplitudes areas in the northeastern part of the study area are better restored due to the implementation of ecological projects, which have resulted in greater vegetation improvements in both areas. Note that some areas (e.g., those with 200-400 $\mathrm{m}$ topographic relief amplitudes and 10-20 slopes) will be further significantly degraded, because they are in a valley and the soil is easily eroded; at the same time, vegetation biomass is closely related to soil erosion, so addressing soil erosion will be the focus of future environmental governance efforts (Figures 6-8). 


\subsection{Limitations of the Study and Prospects for Future Studies}

Terrain changes can cause variations in the LAI. In this study, only four factors were considered; namely, elevation, relief amplitude, slope, and aspect, which do not provide a complete description of the topographic complexity. Furthermore, there is no uniform standard for classifying terrain factors. The topography of the TRSR is complex. Refining the complexity of landforms in the study area and analyzing the response of the LAI to spatiotemporal changes in the rugged land surfaces in mountainous areas are two key directions for future research.

In addition, no analysis was conducted for changes in different vegetation types. As an important index of regional ecological function, the LAI reflects vegetation growth. However, vegetation change is a broad concept, and the true LAI is influenced in practice by a variety of factors such as vegetation types, solar radiation, and topography. In fact, the vegetation types are relatively homogeneous and are dominated by alpine meadows and alpine steppe, and the proportion of different tree species is relatively small in the study area (Figure 2). Moreover, this study focus on the relationships between LAI variations with different topographic factors, and the analyses of vegetation types are beyond the scope of this paper, we will concentrate on the relationship between LAI variations and different vegetation types in the future.

Note that remote sensing products are only an estimation of the true LAI. Algorithms for existing LAI products tend to ignore the influence of topography, and it has been shown that the percentage of successful retrievals for MODIS and GLASS is vulnerable to topographic indices, especially to relief amplitude [33]. However, the differentiation pattern in different terrains for the LAI product is unclear especially in the TRSR, so the focus of this manuscript is to discuss the patterns of LAI variability in long time series under different topography, and not to discuss the influence of topography on LAI variation.

Finally, the influencing factors of spatiotemporal variations in vegetation are extremely complex and result from multiple factors, such as rainfall, temperature, radiation, topography, and human activities. In-depth exploration of the causes of LAI changes requires a combination of meteorological data, land use data, and other relevant data.

\section{Conclusions}

In this study, the temporal and spatial variations in interannual LAI values and their relationships with topographic factors in the TRSR were analyzed using GLASS LAI data and a DEM supplemented with Theil-Sen trend analysis, coefficients of variation, and the Hurst index. The main conclusions are as follows:

(1) In terms of temporal variations, the mean LAI value fluctuated between 0.72 and 0.80 , and the overall vegetation growth showed an increasing trend with a growth rate of $0.013 \cdot 10 \mathrm{a}^{-1}(p>0.05)$.

(2) As for spatial distributions, the LAI was high in the east and low in the west and gradually decreased from southeast to northwest. In addition, the overall LAI stability was high and the spatial variability of the LAI in areas with low vegetation cover was strong. Furthermore, trend analysis showed that areas with improved LAI were larger than areas with degradation. Finally, the Hurst index displayed that the current tendencies in the TRSR are weakly anti-sustaining.

(3) The mean LAI value showed a first increasing and then decreasing pattern as a function of elevation, and an increasing pattern with the increase of slope and relief amplitude. However, no clear pattern was found between mean LAI value and aspects. Further, LAI stability gradually improved as the increasing slope, and the differentiation patterns of stability with relief amplitude, elevation, and aspect were not obvious.

(4) The ratios of significant improvement decreased with increasing elevation, slope, and relief amplitude. The proportions of significant improvement were greatest at lower elevations and in flatter terrain (e.g., areas with elevations less than $3500 \mathrm{~m}$, slopes less than $10^{\circ}$, and relief amplitudes of 1-100 m), while the ratios of significant degradation were greatest at middle altitudes and in rugged terrain (e.g., areas with elevations of 3500- 
$4500 \mathrm{~m}$, slopes of $15-20^{\circ}$, and relief amplitudes of 200-300 m). Additionally, as the aspect shifted from sunny to shady, the overall LAI stability became worse and the improvement and sustainability improved. Note that vegetation degradation will be further aggravated by the steep terrain in the southern part of the TRSR (e.g., Gande, Jiuzhi, and Banma etc.).

This paper discussed the differing variation patterns of LAI in the TRSR for different terrains and led to the conclusion that future ecological restoration, construction and protection projections should focus on science-based conservation of natural vegetation in complex terrains to prevent soil erosion in mountainous areas while simultaneously coordinating the relationship between humans and land to protect and improve the ecological environment, and to promote the healthy and sustainable development of the TRSR.

Author Contributions: Conceptualization, Wenqi Zhang and Huaan Jin; formal analysis, Wenqi Zhang and Wenjie Fan; investigation, Wenqi Zhang and Wenjie Fan; resources, Huaiyong Shao, Ainong Li and Huaan Jin; writing-original draft, Wenqi Zhang and Shangzhi Li; writing-review and editing, Huaan Jin, Ainong Li, and Huaiyong Shao; supervision, Huaan Jin, Ainong Li, and Huaiyong Shao; funding acquisition, Huaan Jin and Ainong Li. All authors have read and agreed to the published version of the manuscript.

Funding: This research was supported jointly by National Key Research and Development Program of China (Grant No. 2016YFA0600103), National Natural Science Foundation of China (Grant No. 41671376, 42071352, 41801370), and Sichuan Science and Technology Program (Grant No. 2019YJ0007). We are grateful to the anonymous reviewers for their valuable comments and suggestions.

Institutional Review Board Statement: Not applicable.

Informed Consent Statement: Not applicable.

Data Availability Statement: (1) The GLASS LAI data presented in this study are available in [http: / / www.geodata.cn/data / datadetails.html? dataguid=9049007\&docId=7758] at [doi:10.12041/geodata. GLASS_LAI_modis $(1 \mathrm{~km}) \cdot$ ver1.db], reference number [21,31]. (2) DEM data can be found here: [http:/ / www.gscloud.cn/sources/accessdata/421?pid=302].

Acknowledgments: The authors would like to thank teachers and work fellows of Research Center for Digital Mountain and Remote Sensing Application, Institute of Mountain Hazards and Environment for their support during this research. Meanwhile, we thank professor Zhiqiang Xiao for providing the GLASS LAI product for us. Moreover, thanks for the anonymous reviewers and all the editors who contributed to their comments and suggestions to improve the quality of the manuscript in the process of revision.

Conflicts of Interest: The authors declare no conflict of interest.

\section{References}

1. Cramer, W.; Bondeau, A.; Woodward, F.I.; Prentice, I.C.; Betts, R.A.; Brovkin, V.; Cox, P.M.; Fisher, V.; Foley, J.A.; Friend, A.D.; et al. Global response of terrestrial ecosystem structure and function to $\mathrm{CO}_{2}$ and climate change: Results from six dynamic global vegetation models. Glob. Chang. Biol. 2001, 7, 357-373. [CrossRef]

2. Hu, M.Q.; Mao, F.; Sun, H.; Hou, Y.Y. Study of normalized difference vegetation index variation and its correlation with climate factors in the three-river-source region. Int. J. Appl. Earth Obs. Geoinf. 2011, 13, 24-33. [CrossRef]

3. Liu, Z.; Shao, Q. Vegetation Coverage Change and Its Response to Climate Change in Three-River Headwaters Region. Res. Soil Water Conserv. 2014, 21, 334-339. [CrossRef]

4. Tang, H.; Xiao, F.; Zhang, Q.; Shi, J. Vegetation Change and Its Response to Climate Change in Three-River Source Region. Adv. Clim. Chang. Res. 2006, 2, 177-180. [CrossRef]

5. Zhu, W.; Mao, F.; Xu, Y.; Zheng, J.; Song, L. Analysis on response of vegetation index to climate change and its prediction in the Three-Rivers Source Region. Plateau Meteorol. 2019, 38, 693-704. [CrossRef]

6. Chen, Q.; Zhou, Q.; Zhang, H.; Liu, F. Spatial disparity of NDVI response in vegetation growing season to climate change in the Three-River Headwaters Region. Ecol. Environ. Sci. 2010, 19, 1284-1289. [CrossRef]

7. Li, H.; Liu, G.; Fu, B. Response of vegetation to climate change and human acticity based on NDVI in the Three-River Headwaters region. Acta Ecol. Sin. 2011, 31, 5495-5504. [CrossRef]

8. Zhang, Y.; Zhang, C.; Wang, Z.; Chen, Y.; Gang, C.; An, R.; Li, J. Vegetation dynamics and its driving forces from climate change and human activities in the Three-River Source Region, China from 1982 to 2012. Sci. Total Environ. 2016, 563, 210-220. [CrossRef]

9. Du, J.; Jiaerheng, A.; Zhao, C.; Fang, S.; Liu, W.; Yin, J.; Yuan, X.; Xu, Y.; Shu, J.; He, P. Analysis of vegetation dynamics using GIMMS NDVI3g in the Three-Rivers Headwater Region from 1982 to 2012. Acta Prataculturae Sin. 2016, 25, 1-12. [CrossRef] 
10. Liu, X.; Ren, Z.; Lin, Z.; Liu, Y.; Zhang, D. The spatial-temporal changes of vegetation coverage in the Three-River Headwater Region in recent 12 years. J. Geogr. Sci. 2013, 68, 897-908. [CrossRef]

11. Jing, M.; Cai, F.; Wang, X.; Zhao, X.; Su, Y. The vegetation coverage spatial characteristics in the Three-River source region. J. Arid Land Resour. Environ. 2020, 34, 141-147. [CrossRef]

12. Xiao, T.; Wang, C.; Feng, M.; Qu, R.; Zhai, J. Dynamic Characteristic of Vegetation Coverage in the Three-River Source Region form 2000 to 2011. Acta Agrestia Sin. 2014, 22, 39-45. [CrossRef]

13. Liu, L.; Yan, J.; Li, S. Spatial-temporal Characteristics of Vegetation Restoration in Qinghai Province from 2000 to 2009. Bull. Soil Water Conserv. 2014, 34, 263-267. [CrossRef]

14. Sun, Q.; Li, B.; Xu, L.; Zhang, T.; Ge, J.; Li, F. Analysis of NDVI change trend and its impact factors in the Three-River Headwater Region from 2000 to 2013. J. Geo-Inf. Sci. 2016, 18, 1707-1716. [CrossRef]

15. Liu, J.; Xu, X.; Shao, Q. Grassland degradation in the “Three-River Headwaters" region, Qinghai Province. Acta Geogr. Sin. 2008, 18, 259-273. [CrossRef]

16. Zhang, X.; Shao, J.; Huang, L. Spatial-Temporal Patterns of Grassland Gradation in Southern part of the Headwaters of the Three Rivers, Qinghaiin China. J. Geo-Inf. Sci. 2008, 10, 645-650. [CrossRef]

17. Wang, Y.; Guo, Y. Analysis of Spatial Correlation Between Vegetation Coverage and Terrain Factors in Karst Landform-Taking Puding Area in Guizhou for Example. Resour. Environ. Yangtze Basin 2018, 27, 157-167. [CrossRef]

18. Zhu, L.; Xie, S.; Yang, H.; Ma, M. The Response of Dynamic Change in Vegetation Coverage to Topography in Chongqing Based on MODIS EVI. J. Nat. Resour. 2017, 32, 2023-2033. [CrossRef]

19. Liu, L.; Zhan, C.; Hu, S.; Dong, Y. Vegetation change and its topographic effects in the karst mountainous areas of Guizhou and Guangxi. Geogr. Res. 2018, 37, 2433-2446. [CrossRef]

20. Gao, M.; Piao, S.; Chen, A.; Yang, H.; Janssens, I.A. Divergent changes in the elevational gradient of vegetation activities over the last 30 years. Nat. Commun. 2019, 10, 2970. [CrossRef]

21. You, Q.; Chen, D.; Wu, F.; Nick, P.; Cai, Z.; Bodo, A.; Jiang, Z.; Wu, Z.; Kang, S.; Agha, K. Elevation dependent warming over the Tibetan Plateau: Patterns, mechanisms and perspectives. Earth-Sci. Rev. 2020, 210, 103349. [CrossRef]

22. Burnett, M.R.; August, P.V.; Brown, J.H.; Killingbeck, K.T. The Influence of Geomorphological Heterogeneity on Biodiversity I. A Patch-Scale Perspective. Conserv. Biol. 1998, 12, 363-370. [CrossRef]

23. Nichols, W.F.; Killingbeck, K.T.; August, P.V. The influence of geomorphological heterogeneity on biodiversity II. A landscape perspective. Conserv. Biol. 1998, 12, 371-379. [CrossRef]

24. Xie, X.; Li, A.; Jin, H.; Yin, G.; Bian, J. Spatial Downscaling of Gross Primary Productivity Using Topographic and Vegetation Heterogeneity Information: A Case Study in the Gongga Mountain Region of China. Remote Sens. 2018, 10, 647. [CrossRef]

25. Sun, L.Q.; Xiao, X.; Feng, F.X. Spatio-temporal pattern of NPP and related analyses with terrain factors in Wuling mountainous area. J. Geo-Inf. Sci. 2014, 9260, 915-924. [CrossRef]

26. Wu, Y.; Ma, Y.; Wu, H.; Xiao, Y.; Li, H. Characteristics of Temporal and Spatial Evolution and Driving Force of Vegetation Index in Sichuan Based on MODIS-EVI. Res. Soil Water Conserv. 2020, 27, 230-236, 243. [CrossRef]

27. Chen, J.M.; Black, T.A. Defining Leaf-Area Index for Non-Flat Leaves. Plant Cell Environ. 1992, 15, 421-429. [CrossRef]

28. Li, A.; Yin, G.; Jin, H.; Bian, J.; Zhao, W. Principles and Methods for the Retrieval of Biophysical Variables in Mountainous Areas. Remote Sens. Technol. Appl. 2016, 31, 1-11. [CrossRef]

29. Baret, F.; Hagolle, O.; Geiger, B.; Bicheron, P.; Miras, B.; Huc, M.; Berthelot, B.; Nino, F.; Weiss, M.; Samain, O.; et al. LAI, fAPAR and fCover CYCLOPES global products derived from VEGETATION-Part 1: Principles of the algorithm. Remote Sens Environ. 2007, 110, 275-286. [CrossRef]

30. Myneni, R.B.; Hoffman, S.; Knyazikhin, Y.; Privette, J.L.; Glassy, J.; Tian, Y.; Wang, Y.; Song, X.; Zhang, Y.; Smith, G.R.; et al. Global products of vegetation leaf area and fraction absorbed PAR from year one of MODIS data. Remote Sens Environ. 2002, 83, 214-231. [CrossRef]

31. Xiao, Z.; Liang, S.; Wang, J.; Chen, P. Use of General Regression Neural Networks for Generating the GLASS Leaf Area Index Product From Time-Series MODIS Surface Reflectance. IEEE Trans. Geoence Remote Sens. 2013, 52, 209-223. [CrossRef]

32. Xiao, Z.; Liang, S.; Wang, J.; Xiang, Y.; Zhao, X.; Song, J. Long-Time-Series Global Land Surface Satellite Leaf Area Index Product Derived From MODIS and AVHRR Surface Reflectance. IEEE Trans. Geosci. Remote Sens. 2016, 54, 5301-5318. [CrossRef]

33. Jin, H.; Li, A.; Bian, J.; Nan, X.; Zhao, W.; Zhang, Z.; Yin, G. Intercomparison and validation of MODIS and GLASS leaf area index (LAI) products over mountain areas: A case study in southwestern China. Int. J. Appl. Earth Obs. Geoinf. 2017, $55,52-67$. [CrossRef]

34. Editorial Committee for Vegetation Map of China. Vegetation Atlas of China; Science Press: Beijing, China, 2001.

35. Xu, X.; Liu, J.; Shao, Q.; Fan, J. The dynamic changes of ecosystem spatial pattern and structure in the Three River Headwaters Region in Qinghai Province during recent 30 years. Geogr. Res. 2008, 27, 829-838. [CrossRef]

36. Fan, J.; Shao, Q.; Liu, J.; Wang, J.; Harris, W.; Chen, Z.; Zhong, H.; Xu, X.; Liu, R. Assessment of effects of climate change and grazing activity on grassland yield in the Three Rivers Headwaters Region of Qinghai-Tibet Plateau, China. Environ. Monit. Assess. 2010, 170, 571-584. [CrossRef]

37. Yang, S.; Zhang, Y.; Chen, S. Extraction of Terrain Relief Amplitude Based on GIS and Change Point Theory. DEStech Trans. Comput. Sci. Eng. (PCMM) 2018. [CrossRef] 
38. Xiong, J.; Zhang, H.; Peng, C.; Fan, C.; Zhu, J.; Gong, Y. Vegetation Variations and Correlations with Topograpgic Factors in Wenchuan Earthquake Area. Bull. Soil Water Conserv. 2018, 38, 24-31, 37. [CrossRef]

39. Cai, B.; Yu, R. Advance and evaluation in the long time series vegetation trendsresearch based on remote sensing. J. Remote Sens. 2009, 13, 1170-1186. [CrossRef]

40. Wang, D.; Liu, W.; Huang, X. Trend analysis in vegetation cover in Beijing based on Sen Mann-Kendall method. Comput. Eng. Appl. 2013, 49, 13-17. [CrossRef]

41. Sun, T.; Li, X.; Xu, M.; Zhang, M. Spatial-temporal variations of vegetation coverage in the Tarim River Basin from 2000 to 2018. Arid Land Geogr. 2020, 43, 415-424. [CrossRef]

42. Lv, Y.; Dong, G.; Yang, S.; Zhou, Q.; Cai, M. Spatio-Temporal Variation in NDVI in the Yarlung ZangboRiver Basin and Its Relationship withPrecipitation and Elevation. Resour. Sci. 2014, 36, 603-611.

43. Qian, S.; Fu, Y.; Pan, F. Climate change tendency and grassland vegetation response during the growth season in Three-River Source Region. Sci. China-Earth Sci. 2010, 53, 1506-1512. [CrossRef]

44. Xu, M.; Kang, S.; Chen, X.; Wu, H.; Wang, X.; Su, Z. Detection of hydrological variations and their impacts on vegetation from multiple satellite observations in the Three-River Source Region of the Tibetan Plateau. Sci. Total Environ. 2018, 639, 1220-1232. [CrossRef]

45. Shen, X.; An, R.; Feng, L.; Ye, N.; Zhu, L.; Li, M. Vegetation changes in the Three-River Headwaters Region of the Tibetan Plateau of China. Ecol. Indic. 2018, 93, 804-812. [CrossRef]

46. Fang, H.; Baret, F.; Plummer, S.; Schaepman-Strub, G. An overview of global leaf area index (LAI): Methods, products, validation, and applications. Rev. Geophys. 2019, 57, 739-799. [CrossRef]

47. Guo, Q.; Li, S.; Hu, Z.; Zhao, W.; Wang, M. Response of Gross Primary Productivity to Water Availability at Different Temporal Scales in a Typical Steppe in Inner Mongolia Temperate Steppe. J. Desert Res. 2015, 35, 616-623. [CrossRef]

48. Shao, Q.; Zhao, Z.; Liu, J.; Fan, J. The characteristics of land cover and macroscopical ecology changes in the source region of three rivers on Qinghai-Tibet Plateau during last 30 years. Geogr. Res. 2010, 29, 1439-1451. [CrossRef]

49. Xiong, J.; Peng, C.; Cheng, W.; Li, W.; Liu, Z.; Fan, C.; Sun, H. Analysis of vegetation coverage change in Yunnan Province based on MODIS-NDVI. J. Geo-Inf. Sci. 2018, 20, 1830-1840. [CrossRef] 